\title{
Asian American Women in the Academy: Multiple Success Case Study of their Leadership Labyrinths and Practices
}

\author{
Dao Nguyen ${ }^{1}$ \\ University of Pittsburgh
}

\begin{abstract}
This paper sheds light on academic leadership pathways and practices of Asian American women (AAW) in higher education in the United States (U.S.) under intersectionality of social and institutional identities/elements. The preliminary intersection model of these identities/elements is the ultimate outcome of the paper. The paper is crystalized from an empirical study founded on intersectionality concept and leadership theories in general, and on established knowledge base of AAW and leadership in particular. The multiple case study method (MCSM) and success case method (SCM) were employed in combination to examine four AAW cases, which were purposively selected from four 4-year-universities in California and Pennsylvania. The data source primarily came from in-depth semi-structured interviews. The data analysis on NVivo 12 revealed that AAW's leadership pathways and practices were influenced and shaped by social identities of individuals (gender, racelethnicity, class, and culture), and institutional cultures (tangible and intangible). Religion and female role models in family, graduate study, and workplace were found as additive elements impacting AAW's leadership experiences. These multiple identities and elements intersected with each other in different ways to feature lived experiences of $A A W$ in academic leadership. The study responded to recent calls for applying incorporation approach of leadership and diversity in research on leadership. It also supported the existing literature on leadership pipelines and experiences of $A A W$ in the academy. The research was among few qualitative studies in the AAW leadership scholarship using the NVivo program in data management, analysis, and presentation. The preliminary intersection model of social and institutional identities/elements influencing and shaping $A A W$ 's leadership in the academy could imply direction for further study on $A A W$ and leadership not only in academe but also in other areas.
\end{abstract}

KEYWORDS: Asian American Women, Leadership Labyrinth, Multiple Success Case Study, Preliminary Intersection Model of Social and Institutional Identities/Elements.

\section{Introduction}

The Asian American population in the U.S. has grown in both number and diversity since the 1965 Immigration and National Act was passed (Hune, 2020a, 2020b; Liang \& PetersHawkins, 2017). It has been one of the major racial or ethnic groups of the fastest growth rate. It increased 72 percent between 2000 and 2015 (from 11.9 million to 20.4 million). It is estimated to become the largest ethnic group in 2055. California, New York, Texas, New Jersey, Hawaii, Illinois, Washington, Florida, Virginia, and Pennsylvania are the ten states with the largest Asian population which makes nearly three-fourths of the entire Asian American

\footnotetext{
${ }^{1}$ Corresponding Author E-mail: dao.ng@ pitt.edu
} 
population in the U.S. Current Asian Americans are originally from more than twenty Asian countries (Bakalar, 2017; Lopez et al., 2017; US Census, 2010, as cited in Hoeffel et al., 2012). Kawahara (2008), Kawahara et al. (2020), and Nguyen (2016) point out in their studies that each Asian American, particularly Asian American woman (AAW) has original personal experiences in their life and profession due to her family, immigration and profession histories. Moreover, AAW possess a variety of identities connected to their gender, race, ethnicity, culture, and others.

Asian Americans rank high in college and university enrollment, in profession, and household income. However, AAW have persisted in underrepresentation across the time in leadership, particularly in top positions (AAUW, 2016; Chen \& Hune, 2011; Espinosa et al., 2019; Hune, 1997, 1998, 2002, 2006; Karahara \& Chin, 2013, Lee \& Zhou, 2015; Park et al., 2014). In the academy, although number of tenured Asian American faculty makes up higher proportion ( 7 percent) than that of other minority groups, Asian American deans account for only 3 percent (Prinster, 2016).

Since the Asian American Studies; and Gender and Leadership were introduced in the U.S. in the 1970s, there have been series of empirical studies repetitively seeking rigorous explanations for such underrepresentation of AAW in academic and non-academic leadership. The overwhelming majority of the studies figure out that invisible barriers connected to gender, race, and culture stereotypes and prejudice have made "leaks" of the educational and professional pipelines of AAW. Most of the research works of Hune (1997, 1998, 2002, 2006, 2011, 2020) documented that institutional elements as a whole and together have inhibited AAW's success in profession career in the academy. Meanwhile the literature of Kawahara et al. (2007, 2013, 2020) mostly focused on lived experiences of AAW in their leadership pathways. Other scholars such as Eagly and Chin (2010) and Chin (2012, 2020) concentrate their studies on looking for more appropriate approach for scholarship of AAW's leadership. They also explore lived experiences of individual AAW to point out barriers and to search for key personal and institutional facilitators for these women to successfully move up to decisionmaking positions in higher education.

It is apparent that increasing number of scholars have greatly contributed to building up the knowledge base of AAW's leadership. Their studies illuminate salient personalities of individual AAW and institutional fundamental changes, which have supported AAW to advance to leadership in academic and administrative posts. However, there has been an absence of research literature evidently delineating the degree of the intersection between multiple social and institutional identities influencing and shaping AAW's leadership trajectories and practices. A question is thus raised - Have the identities intersected with each other at the same strength to impact AAW's leadership, or does each identity have its own strength in the intersection?

In terms of methods, qualitative research has been a "legacy" of research studies in the field of AAW and leadership. However, very few of them employed NVivo program ${ }^{2}$ as an

\footnotetext{
2 "NVivo is a computer program for qualitative data analysis that allows one to import and code textual data, edit the text; retrieve, review and recode coded data; search for combinations of words in the text or patterns in the coding; and import from or export data to other quantitative analysis software. NVivo was developed by QSR International, the makers of NUD*IST. QSR's first product was created in 1981 (then called NUD*IST) to support social science research and contained tools for innovative 'Non-Numerical Unstructured Data Indexing Searching and Theorizing'. The product suites and services offered by QSR have evolved over the years (Bandara, 2006, p. 7). NVivo 12 is the second latest version after the newest version released in March, 2020.
} 
alternative qualitative data analysis software. At least, the author could find Reeves' (2014) study as the most recent research making use of this software in data management and analysis.

Moreover, in broader field of leadership, Chin (2013) argues, "Current theories of leadership have been relatively narrow in their incorporation of diversity; the theories generally portray a White, Anglo, North American, heterosexual male biased view of leadership" (p. 235). She thus proposes a model of diversity leadership, which is "inclusive, respectful of differences, empowering, collective, and oriented to social change" (p. 238).

The gap in current scholarship of leadership and AAW leadership, and research technique noted above persuaded the author to continue the same research inquiry as that of contemporary scholars on AAW in leadership in academe; but in more focused approach and broader framework. First, the study intensively focused in AAW in leadership positions related to academics (vice president/vice chancellor for academic affairs, dean/associate dean, department chair/head, academic/research center director, academic program director or the same). Second, culture was set as constant identity across cases of the study. Accordingly, only AAW originally from Asian societies under strong impact of Confucianism like mainland China, Hong Kong, Taiwan, Vietnam were chosen to participate in the study. Third, the conceptual framework was broader, including not only the established knowledge base of AAW and leadership in the academy, but also intersectionality concept, and leadership theories related to gender and culture.

The study concentrated on addressing the following three research questions:

1. What are leadership pathways of Asian American women in the academy in the U.S.?

2. What personal and institutional identities/elements have influenced and shaped their leadership pathways and practices in the academy?

3. How have the identities/elements found in the second question intersected to impact and shape AAW's leadership pathways and practices in the academy?

The answers to the first two questions would confirm, enrich, or challenge the existing literature on AAW and leadership in the academy. The last question would provide a preliminary intersection model of personal and institutional identities/elements sought in the second question.

\section{Literature Review and Conceptual Framework}

The inquiry of my study on AAW's academic leadership in the U.S. academy was situated in a broader area of study - AAW and leadership in general. The bibliometric analyses available on the Scopus and Web of Science databases informs that AAW and leadership in the U.S. is a new field of study. Although Asian American Studies, and Gender and Leadership were introduced in the 1970s (Chemers, 1997; Hoyt \& Simon, 2016; Huang, 2008), the record of AAW and leadership scholarship started available on the indexed databases two decades later, i.e. from the 1990s. Since then the area of AAW and leadership has drawn increasing attention of scholars. Figure 1 visualizes the trend of research literature on AAW and leadership by volume in the past three decades on the Scopus and Web of Science. 


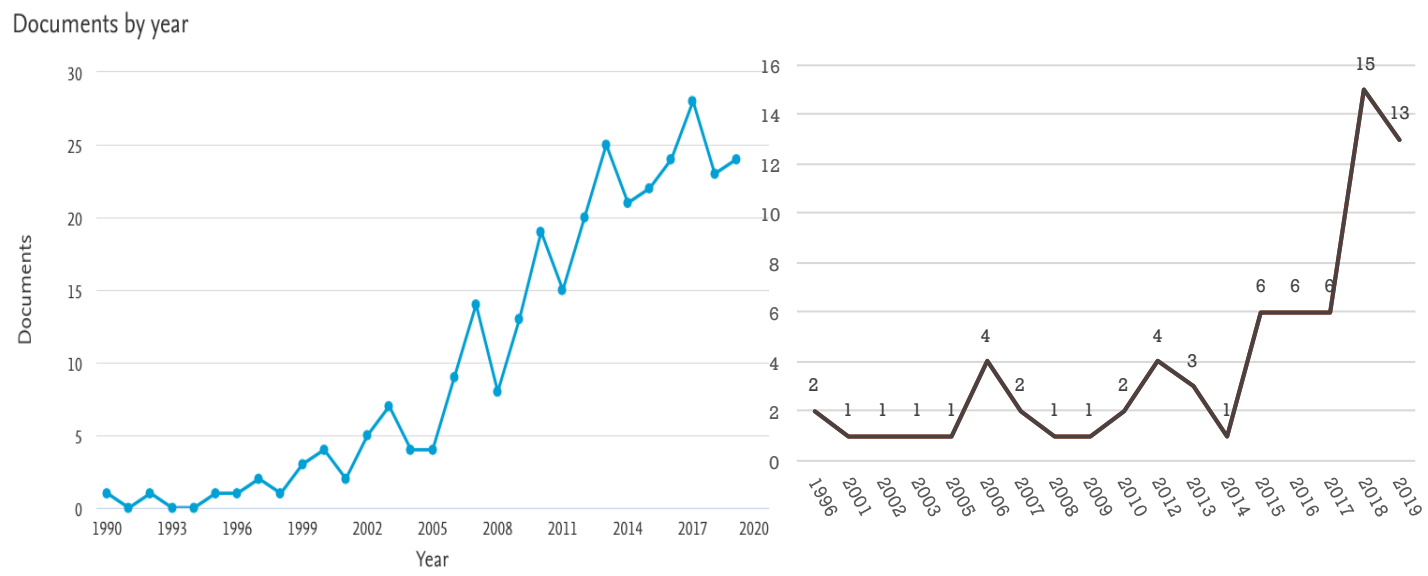

Figure 1. Volume by Year

Regarding intellectual structure ${ }^{3}$, the science mapping method with the support of VOSviewer and data sources also obtained from Scopus and Web of Science databases provides that the area of the AAW \& leadership has been founded heavily on the conceptual and theoretical framework of intersectionality, gender and leadership, feminism, ethnicity, and race. And the issues studied were mostly related to stereotype, racism, diversity, social justice, and identity (Figure 2).

Scopus

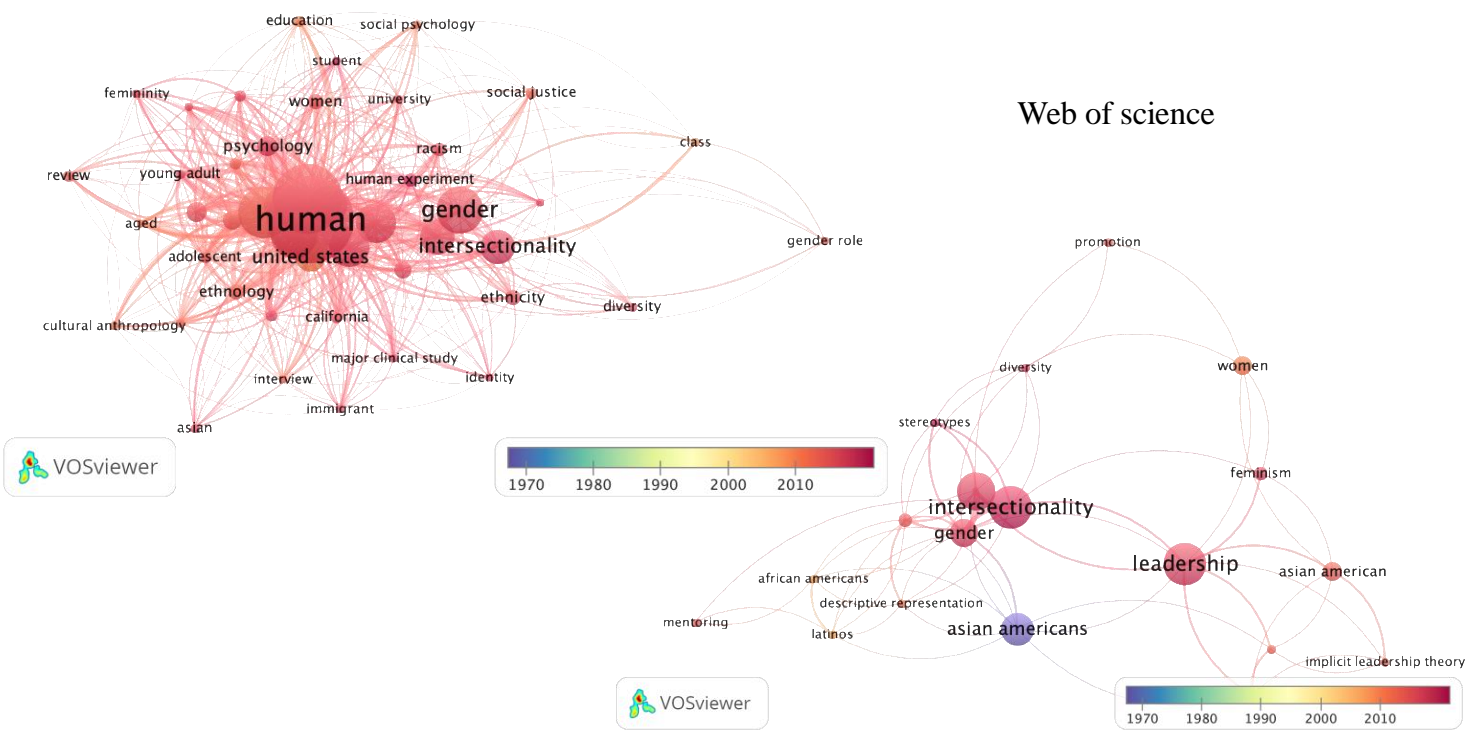

Figure 2. Intellectual Structure of AAW and Leadership Area

More specifically in the U.S. academe, the existing literature of AAW and leadership prevalently focused on exploring the leadership pathways and practices of AAW in higher education.

\footnotetext{
${ }^{3}$ Intellectual structure refers to key theoretical and empirical lines of inquiry, or "schools of thought" (Punnakitikashem \& Hallinger, 2019)
} 
For leadership pathway, Hune (2011) closely examines the "gains" and "leaks" of Asian American Pacific Islander (AAPI) women's trajectories from Ph.D. to campus president, based on the national statistical data 2007 from the U.S. Department of Education. She highlights that there has been a large number and an increasing trend of AAPI female students enrolled in higher education, but underrepresenting number of AAPI female faculty, particularly in the top leadership posts. This gap could inform some leaks on the pipeline of their moving from doctoral studies to advanced positions in academia like full professoriate rank and campus presidents. Before and after Hune's (2011) study, many studies have also provided evidence of invisible barriers causing "leaks" in AAW's paths to leadership. The barriers include prejudice and stereotype related to gender, race, and culture; unjust treatment of their institutions in hiring, evaluating, and promoting; and personal difficulties such as disadvantaged socioeconomic status, language barrier, and heavy home-work responsibilities (Asher, 2010; Loo \& Ho, 2006; Chin, 2012, 2020; Hune, 1997, 1998, 2002, 2006, 2020a, 2020b; Kawahara, 2007; Liang \& Peter-Hawkins, 2017; Loo \& Ho, 2006). Li and Beckett (2006) conceptualize these barriers as sociocultural, political academic, and personal issues. Most recently, Chin (2020) puts those challenges in another way under pairs of contrasts confronting AAW in leadership journeys - men versus (vs.) women behavior in leading, Western vs. Asian culture, work vs. home responsibilities. Also in 2020, Kawahara and her colleagues add another pair of contrasts labeled "duality in leadership role". They explain that in one end, AAW leaders experience decision-making power by their leading position; but in the other end, they undergo "the microaggressions of being ignored, dismissed, or mistreated based on the intersectionalities of race/ethnicity, gender, social class, size, and other identity dimensions and social locations" (p.86).

In order to support AAW to overcome those invisible barriers to advance to leadership, Eagly and Chin (2010) offer fundamental suggestion for scholarship. They propose that the intellectual base of AAW and leadership should link "two bodies of theory and research - one pertaining to leadership and the other to diversity" (p. 216). They also insist diversity as a way to practice and promote established democracy value in the academy. Then Chin (2012) drawing from her own experience in the journey to leadership in academe proposes that higher education institutions should sustain the established principles of academic freedom and shared governance as "big equalizers" (p. 155). Meanwhile, systematic and transformative changes should be made to eliminate discrimination related to gender, race, and culture. The academy has been viewed as an agent of social changes, and also as a venue for racism, gender discrimination, xenophobia, and other injustices to persist (Hune, 1997, 1998, 2006, 2002, 2020b). Hune (2006) agrees with the point raised by Tierney et al. (2004) to propose that the notion of competence and authority should be defined based on culture and social construct. A diverse environment featured by a "culturally pluralistic" atmosphere should be nurtured for all members of institutions to "achieve fully" (p. 15).

For leadership practices, research studies of Asher (2010), Kawahara et al. (2020), Kawahara (2007), and Kawahara and Chin (2013) gave distinctive images of AAW leaders in terms of their leading styles and behaviors shaped by their own identities associated with culture, gender, and race. They led "in response to the urging of others, using a group orientation and collaborative style, having a strong work ethics, emphasis on excellence" (Kawahara et al., 2013 , p. 240). These authors also reveal that such key personalities as resiliency, selfempowerment, courage in struggling against injustices, integrity, and pride and confidence have helped AAW overcome invisible barriers. Encouragement and mentorship are catalysts for AAW to advance to leadership. Kawahara et al. (2020) insist that mentorship is one of the most important facilitators in the leadership pathways and practices of AAW. Mentorship is needed for AAW in all crucial aspects of their leadership lives, from professionalism, scholar work, opportunities, to leading styles and behaviors. 
In addition to existing scholarship of AAW and leadership as presented above, my study also relied broadly on the concepts of women's leadership labyrinth and intersectionality, and the theories of leadership related to gender and culture, and cultures of academy. Rationally, Asian American leaders embrace in themselves at least identities of gender and race/ethnicity. And race/ethnicity and culture are closely connected. For intersectionality, Liang and PetersHawkins (2017) recommend that intersectionality studies, which originally centered on interplaying of the social constructed identities such as gender, race, ethnicity, and class to get insights into Black women and Latino/Hispanic women as the oppressed in their social lives, should be expanded to AAW. The persistent underrepresentation of AAW in the academy across the time informs that they are also the oppressed in their organizations like women of other colors.

The concept of women's leadership labyrinth is introduced by Eagly and Carli (2007). They use the metaphor of labyrinth to delineate a complex journey full of "twists and turns" experienced by women in their leadership journeys in different work areas. The "twists and turns" pertain to women's role at work and in family as wife and mother, social prejudice on women leadership, and institutional cultures. On the other hand, the authors emphasize that the leadership labyrinth was worthy for women to make their best efforts to conquer it. Once a woman has succeeded in her leadership labyrinth, she could effectively support other women to advance in their social lives.

The concept of intersectionality is coined by Crenshaw $(1989,1991)$. The term "intersectionality" refers to "the phenomenon of the merging and mingling of multiple markers of difference or "intersection" (Crenshaw, 1989, p. 246). Crenshaw (1991) criticizes the contemporary U.S. law as a white-supremacist-patriarchy entailing mechanism of marginalizing women of color. She also argues that the failure of antiracist and feminist activism in supporting women of color from oppression are due to isolating consideration of race and gender. She thus proposes for a deeper examination of the intersection of race and gender on every issue facing women of color.

The Gender and Leadership was emerged in the 1970s when the number of women in leadership positions, especially in academia, was increasing. Since then, there has been more rigorous research on gender and leadership. The research question evolved from "Can women lead?" to "Do men and women lead differently?", "Are men more effective leaders than women?", and most recently "Why are women underrepresented in elite leadership roles?" (Chemers, 1997; Hoyt \& Simon, 2016, p. 397-398). The empirical answer to the latest question "Why are women underrepresented in elite leadership roles?" is because of invisible barriers stemmed from prejudice, stereotype, discrimination related to gender, race, culture, and other identities for women. Northouse (2016a) clusters invisible barriers of women's leadership labyrinth into three categories - (1) Human Capital regarding education, work experience, development opportunities, work-home conflict; (2) Gender Differences in style and effectiveness, commitment and motivation, self-promotion, negotiation, and traits; and (3) Prejudice associated with gender stereotypes, biased perception and evaluation, vulnerability and reactance, and cross-pressure.

Regarding culture, Northouse (2016b) points out that culture and leadership started to be discussed and studied after the World War II when globalization has been enhanced around the world. The globalization raised the demand to understand the impact of different cultural bases on leadership performance. Culture by Gudykunst and Ting-Toomey's (1988) definition refers to learned beliefs, values, rules, norms, symbols, and traditions, which are common to a group of people. House et al. (2019) drawing the GLOBE Study of 62 Societies conducted by House et al. (2004) illuminate that people belonging to the Confucian Asia cluster - one of 10 
distinctive clusters ${ }^{4}$ categorized by culture - have high score in cultural dimensions of in-group collectivism, institutional collectivism, and performance orientation. In terms of leadership behaviors, Confucian Asians are more self-protection, team orientation, and humane orientation. In leading, they are independent and somewhat inspiring, but do not expect others to participate much in goal setting or decision making.

As my study focused on leadership of AAW in the academy, perception of Bergquist and Pawlak (2008) on cultures of the academy were also drawn to frame my research inquiry. The authors articulate six cultures affecting the leadership in academia. They are collegial, managerial, developmental, advocacy, virtual, and tangible cultures. Collegial culture refers to the traditional nature of campus settings emphasizing academic faculty culture, liberal arts traditions, and research and scholarship. Managerial culture stresses on the effectiveness and efficiency of institutional management. The developmental culture is associated with faculty development, curriculum expansion, and institutional research. The advocacy culture is embraced in faculty unions, collective bargaining, and academic freedom. Virtual and tangible cultures are the two added cultures in their literature. The virtual one is mentioned as "the technological invention "such as the internet, computers, cell phones and "the advent of online and virtual universities" (p. 131). This culture has impacted personal and professional lives in higher education. The second added culture is tangible one. It is characterized by space, architecture, and pedagogy of the institution and it is thought to make some impacts on the leadership.

To sum up, my research on AAW's leadership in the academy was grounded on the existing knowledge base of leadership pathways and practices of AAW in higher education context. To broader extent, my study was also framed on the concepts of leadership labyrinth and intersectionality; and leadership theories related to gender, culture, and institutional cultures.

\section{Methods}

To seek the empirical answers to the research questions, the study employed qualitative research method to obtain thick, accurate, precise, and broad data which could illuminate AAW's lived experiences in the academic leadership (Becker, 1996). Regarding the research technique, I applied case study approach in data collection and analysis proposed by Stake (1995). Specifically, my study employed multiple case study termed and elaborated by Yin (2003). Both Stake (1995) and Yin (2003) recommend that case study should be based on constructive paradigm which "recognizes the importance of the subjective human creation of meaning, but does not reject outright some notion of objectivity" (Crabtree \& Miller, 1999, p. 10). Each case in my multiple case study was regarded as a success case worth to be studied. The Success Case Method (SCM) introduced by Brinkerhoff (2003) was used to seek what have shaped their success of AAW in their academic career in American higher education context. Although success case study method does not sound popular in educational research, it has been widely used in a wide range of areas (healthcare, rural development, child adoption, social welfare, manufacture and many others) in the last decade of the $20^{\text {th }}$ century and contemporary time to "determine why [a] person was successful - especially to identify the organizational factors, supervisory assistance, for example, that supported and enabled the success" (p. 20). In the field of education, scholars and researchers more employ the term "case study" proposed by Stake (1995), and Lincoln and Guba (1985).

Brinkerhoff (2013) articulates that stories shared by successful people are in the center of SCM. "Storytelling is as old as people themselves and has always been a powerful

\footnotetext{
${ }^{4}$ Ten distinctive clusters by culture: Anglo, Germanic Europe, Latin Europe, Sub-Saharan Africa, Eastern Europe, Middle East, Confucian Asia, Southern Asia, Latin America, and Nordic Europe (Northouse, 2019, p. 440)
} 
influencer...The power of stories is well known to most of us from your life experience in general" (p. 18). Regarding data collecting instrument and procedure, he suggests that a Success Case study should first starts with "a search for stories of success worthy of the telling", then is proceeded with interviews with people of success stories to "uncover evidence" of the success shaping factors (p. 19). He insists that SCM is scientific based on "solid rules and the discipline of scientific inquiry" (p. 25). Moreover, he affirms that the interview technique in SCM literally depend on rules of good naturalistic inquiry and reporting established by Lincoln and Guba (1985).

Based on Lincoln and Guba's (1985), Stake's (1995), Yin's (2003), and Brinkerhoff's (2003) perspectives, I selected four AAW from 4-year universities in the US for semi-structure in-depth interviews. Each of them was regarded as success case because they have already anchored their career in the academy and been credited to academic leading posts in their institutions for at least two years at the time of the interview.

\section{Sampling}

My sampling followed the guidelines of Daniel (2012) on non-probability sampling because the purpose of my study was exploratory and also explanatory about the academic leadership labyrinth of AAW in higher education in the U.S. Moreover, the purpose of my sampling was to "provide illustrative example[s]" (p. 68) to be studied. The "examples" focused on successful experience in order to imply good lessons for other people of the same gender, race in the same social and institutional context. Limited time and financial resources were also reasons for my sampling choice and size. The specific technique of this sampling was purposive. Drawing the findings of the US Census Bureau (2010) and American Community Survey (U.S. Census Bureau, 2016) on the distribution of Asian population in the US, I selected ten states accommodating the biggest Asian American population - California (6.33 million), New York (1.80 million), Texas (1.38 million), New Jersey (0.90 million), Hawaii (0.96 million), Illinois (0.76 million), Washington (0.74 million), Florida (0.68 million), Virginia (0.62 million), and Pennsylvania (0.48 million). The reason for selecting these states was to have bigger pool of AAW leaders in higher education for my sampling. Among these ten states, only two states of California and Pennsylvania were chosen because of their top and bottom positions in the top ten states of the biggest Asian population in the U.S. In each state, two Asian American female participants were selected for in-depth interviews based on the following criteria:

- Being originally from China, Japan, Korea, or Vietnam whose culture and tradition are strongly influenced by Confucianism.

- Being currently in academic leadership position (for example, vice president in charge of academics, dean, associate dean, department chair or vice chair, director or vice director of center/division/unit related to academics).

- Being currently employed in different 4-year universities of different types (private and public) in the state and in different professional backgrounds (social sciences and sciences).

Regarding sampling sources, the Association for Asian American Studies (AAAS) was the first main gate. Its official website and publications provided a big pool of AAW in academic leadership across the U.S. The second sampling source was the recommendations from my professors and colleagues.

After identifying the participants satisfying the sampling criteria, the researcher contacted them via email to introduce the research study and interest in interviewing them. If they agreed to participate, an appointment was made for the interview in the form of person-to- 
person or via Skype or Zoom at their best convenience. In the end, there were four Asian American female faculty participating in the study as planned. Their names were coded with pseudo names - Claire (Case 1), Ruth (Case 2), Nancy (Case 3), and Nadia (Case 4). All of them were in academic leadership posts at four-year universities - department chair, academic program director, research center co-director, and senior research team leader respectively.

\section{Data Collection}

The data were collected primarily from in-depth semi-structured interviews for the participants' stories about their pathway to academic leadership and practices in academia. The interview questions were built alongside the specific inquiries noted in the research questions to explore the leadership labyrinths of AAW. The substances of the interview questions were grounded on the conceptual framework presented above. Besides, the interview consisted of questions eliciting emergent senses outside what had been prescribed in the existed concepts and theories. Table 1 below summarizes content and time structure of the interview protocol.

\section{Table 1}

Summary of Content Structure of Interview Protocol

\begin{tabular}{|c|c|c|c|}
\hline Part & Content & $\begin{array}{l}\text { Number of } \\
\text { Questions }\end{array}$ & $\begin{array}{c}\text { Time } \\
\text { Length } \\
\text { (minutes) }\end{array}$ \\
\hline Introduction & $\begin{array}{l}\text { Greeting, brief introduction of research study, interview } \\
\text { sections, and getting the participant's approval for audio- } \\
\text { recording. }\end{array}$ & & 3 \\
\hline \multicolumn{4}{|l|}{ Body: } \\
\hline - Section 1 & $\begin{array}{l}\text { Social, educational, professional, and leadership background } \\
\text { of the participant. }\end{array}$ & 8 & $10-20$ \\
\hline - Section 2 & Leadership pathways and practices. & 14 & $22-32$ \\
\hline - Section 3 & $\begin{array}{l}\text { Facilitators and inhibitors of leadership pathways and } \\
\text { practices. }\end{array}$ & 10 & $16-20$ \\
\hline Conclusion & $\begin{array}{l}\text { Further sharing from the participant and thank-you } \\
\text { statement from the researcher. }\end{array}$ & & $4-6$ \\
\hline
\end{tabular}

Each interview lasted between 53 and 87 minutes and were audio-recorded with the participants' consents. The interviews with Case 1 (Claire) and Case 2 (Ruth) were conducted in their offices; with Case 3 (Nancy) via Zoom, and with Case 4 (Nadia) via Skype because of geographical distance. Prior to the interviews, the IRB Approval and the Research Study background information were provided to the participants. The interview questions were sent to the participants at their request. In fact, only Case 3 (Nancy) asked for the interview questions beforehand. She wanted to prepare her responses well-covering my inquiries because her time for the interview was very tight (fewer than 60 minutes). Their consents for interview participation and audio-recording were obtained before the interviews started.

\section{Data Analysis}

In coding the interview data, the study mainly relied on the guidelines of Saldana (2016) and Miles et al. (2020). The general approach of coding was a combination of deductive and inductive coding. With deductive approach or theory-driven top-down approach (Chi, 1997; Kratt, 2018), nodes as termed in Nvivo 12 language or codes were identified based on the established conceptual and theoretical framework. With inductive approach or data-driven bottom-up approach (Chi, 1997), codes arising from my analysis of the original data were 
labelled with new category(ies) and theme(s). The unit of coding analysis was first by single interview transcript, then inside each transcript by sentence and response/passage.

The coding process was conducted through two stages or cycles. The first stage opencoding was to identify and label codes. The second stage was to refine or interpret for more analytical themes or categories or clusters.

\title{
First Stage of Coding - Open Coding
}

In the first stage of coding, both grammatical and exploratory methods were employed. In grammatical method, the attribute mechanics was applied to code the descriptive data arisen from the first part of the interview protocol to explore the participants' demographics and pathways to academic leadership (educational preparation, professional choice and retention, and work experience in the US). In exploratory method, the provisional mechanics was employed to code the data obtained from the rest parts of the interview protocol regarding the factors influencing and shaping leadership experiences of the cases. "A priori or start list" (Miles et al., 2020, p. 69) were generated, drawing from conceptual and theoretical framework, research questions, and interview questions. In this cycle, the coding mainly followed deductive approach. In the meantime, the researcher also opened to note down emerging codes. In the process, every single interview's transcript was read and all words and lines in each response or passage giving sense of factors impacting their leadership experiences were highlighted. Lastly, all meaningful codes closely connected with key senses responding to the research inquiry and interview questions were labelled.

In the first cycle of coding, the deductive approach of coding worked well, following the established conceptual and theoretical framework. However, the researcher had to work hard with inductive approach with two issues. The first one was related to the data pieces giving other sense than sense of code generated from the conceptual and theoretical framework. Role model and religion were examples. In data analysis, the researcher found all the four participants shared that their mothers, academic advisors, and work supervisors have influenced their experiences in their leadership practices. And one participant mentioned about her family' religion (Buddhism) influenced her attitude, thinking, and behavior in her work.

The second issue occurred when the sense of one quote could be coded into different nodes. For instance, the following quote from the transcript of interview with Case 3 could be coded into the nodes of race, culture, and also religion (emerging node). The researcher eventually opted to enter this quote into different codes based on its sense. This choice was acceptable because the nature of qualitative research more emphasizes sense-making of the subjects than number of quote occurrence;

\begin{abstract}
I am a Buddhist and I have been get trained as much as early age about the importance of harmony you know within a group and I think it is probably because of Asian culture as well... Culture I think individually because I think in Eastern culture the folks tend to be more about collectivism about harmony about group support and do the best for interests of the group. Western culture is much more individualistic. And I certainly see you know in my early stage and even until now I am not as self-promoted individual (Transcript of interview with Case 3)
\end{abstract}

\section{Second Stage of Coding - Pattern Coding}

Saldana (2016) explains, "First [stage] coding is a way to initially summarize segments of data. Pattern coding, as a second [stage] method, is a way of grouping those summaries into a smaller number of categories, themes, or concepts" (p. 236). From codes/nodes resulted from 
the first stage of coding, based on the research inquiries and the conceptual and theoretical framework, the researcher grouped them into a certain categories/themes of gender, race, class, institutional values, and others.

To sum up, with the availability of qualitative data collected from four in-depth semistructured interviews, the analysis of these data was conducted through two stages of coding. the researcher employed the grammatical and exploratory methods with the mechanics of attribute and provisional coding respectively in the first stage and the pattern method in the second stage. Both deductive and inductive approach, and case-by-case-first-and-then crosscase analysis were followed during the coding process. Table 2 below presents the results of data analysis through two stages of coding.

\section{Table 2}

Data Coding Results by Node/Code on NVivo

\begin{tabular}{lcc}
\hline Parent \& Child Nodes/Codes & Files & References \\
\hline 1- Leadership Pathways & 4 & 41 \\
2- Identities/elements influencing and shaping leadership pathways and practices & 4 & 145 \\
2.1. Gender & 4 & 31 \\
2.2. Race & 4 & 15 \\
2.3. Class (socio-economic background of family) & 4 & 8 \\
2.4. Culture & 4 & 15 \\
2.5. Institutional cultures & 4 & 63 \\
2.6. Role Model & 4 & 12 \\
2.7. Others & 1 & 1 \\
3-Other Sharing & 4 & 15
\end{tabular}

\section{Validity and Reliability}

Merriam (2009) insists that a research study must ensure both internal and external validity. The internal validity refers to the matching between research findings and reality. The author recommended six strategies to enhance internal validity of a study - (1) Triangulation, (2) Member check, (3) Adequate engagement in data collection, (4) Negative or discrepant case analysis, (5) Researcher's position or more recently "reflexivity, and (6) Peer examination or peer review. My study applied Strategy (3) and (6). Before officially collecting the data for my study, I conducted pilot interviews with two faculty from different departments to make sure all interview questions to be clear for participants to provide answers well-covering the research inquiry. After these pilot interviews, some interview questions were reworded and the interview protocol was adjusted to obtain a better flow of meaning through the participants' stories. Moreover, each of interviews lasted long enough (53-87 minutes) to deepen the participant's trajectory of leadership and practice. In order to avoid missing any significant data of the participants' stories, the researcher also used open questions like "What else would you like to share about your leadership pathway and practice?" to elicit emerging data outside the structured themes underneath the interview protocol. Regarding peer review, since this study was counted as a research milestone of my Ph.D. journey, a faculty committee including three professors examined every step of the research from design, data collection and analysis, and findings, to oral and written presentations. My study could obtain critical and scholarly reviews from more than "peers".

External validity in qualitative research pertain to transferability rather than generalizability in quantitative research. Lincoln and Guba (1985) articulate the notion of transferability, "the burden of proof lies less with the original investigator than with the person seeking to make an application elsewhere. The original inquirer cannot know the sites to which transferability might be sought, but the applier can and do" (p. 298). In order to obtain external validity, they suggested the researcher should provide "sufficient descriptive data" to make 
transferability possible (p. 298). The thick description of the data collection and analysis process presented in detail above and the findings presented in case-by-case first and then crosscases below could prove a certain extent of transferability in my study although the sample size was rather small.

Lincoln and Guba (1985) defined reliability in qualitative research as "dependability" or "consistency". It depends on how much the results make sense from collected data. They recommended four strategies to enhance reliability of a study - triangulation, peer examination, investigator' position, and the audit trail. The first three have been discussed above in the Internal Validity. The audit trail refers to detailed description of "how data were collected, how categories were derived, and how decisions were made throughout the inquiry (Merriam, 1988, p. 172). Apparently, the presentation of the methods in the previous section in this paper could prove reliability in this study.

\section{Findings}

\section{Pathways of Asian American Women to Academic Leadership in the US}

\section{Case-by-Case}

Case 1 - Claire. Claire was born and grew up in a middle-class family in Hong Kong, then followed her parents to Canada when she was almost 12 years old. She took undergraduate study in psychology in Canada. Then she moved to the US by herself for her combined master's and doctoral (Ph.D.) program in Social Psychology in the U.S. Her professional title at the time of the interview was Professor of Psychology. She preferred teaching to research and has had social psychology teaching experience at two universities. Her institution at the interview time was a private university located in Pennsylvania. It has been two years since she stepped up first as a co-chair and then chair of the Undergraduate Psychology Program at her university. She was married but has not had children yet. Her husband also worked at another university away from her institution for several hours of driving. They were thus together just during the weekend. She came to the campus with her lovely dog every weekday. She appreciated her institution permitted her to take her pet along with her to the office.

Case 2 - Ruth. Ruth was from Taiwan. She was Associate Professor of Business and Psychology. She held bachelor degree in Psychology, Master's degree in Information in the U.S. and two Ph.D. degrees in Business and Psychology. She had five years of experience in the position of Director of Business Program in a private university in Pennsylvania. She was also from middle class family. His father "was actually a teacher, so he did not have a big business, but he was math teacher but he did run his own school...a pretty successful private school". Her mother was a home maker. At her time, there were a lot students from her father's school chose to apply for medical schools. Being accepted to a medical school was a dream of many families and students because the chance was only $10 \%$ or less. Her test scores were pretty high and potential to be accepted to a medical school. Her parents accordingly wished to see her apply for a medical school, but she had passion for other fields of study - psychology, information science, and business. She shared;

I always wanna become an academic [person], become a scientist that something that I always want to do. I am very academic growing up and I wanna to get my Ph.D. and applied to several schools then I got a full scholarship to [name of the University]. So, I came here 23 years ago on that scholarship (Interview transcript of Case 2). 
She was married and had one boy. Her husband had a job with more flexible work time than hers. He therefore helped her take care of the boy and housework a lot. Like Claire, Ruth are rather young, under 40 years old. Both of them have been in the U.S. for over 20 years and were the first generation of her family anchoring their lives in the U.S.

Case 3 - Nancy. Nancy's case is quite different from cases of Claire and Ruth in her way to migrate to the U.S. and her educational pipeline. Nancy's ethnicity is Vietnamese. She is 1.5 generation of Asian race in her family anchoring their life in the U.S. Nancy and her mother (an elementary school teacher in Vietnam) escaped Vietnam in 1988 when she was eight years old on a small boat which accommodated 18 people travelling along the coasts of different countries. They experienced a "pressured journey" with fear of pirate attack and death. Nancy and her mother arrived in the US after two years and a half of living around refugee camps in Hong Kong and the Philippines. She insisted that what she was were mostly shaped by her mother's strength, courage, and resilience, the opportunities of being exposed to different languages - Vietnamese, Chinese and English as well as all kinds of support she and her mother received from the communities they lived with throughout the journey to the U.S. Her primary education was interrupted because of a long trajectory she and her family had experienced before they came to the U.S. She has been in academic leadership post as a department chair for two years and as a director of an Asian languages center for over 4 years. Her institution is public and located in California. She could be considered as a young and dynamic female leader (38 years old) in her university. She was a mother of two children (three and five years old). Nancy's professional background is psycho-biology in undergraduate major, education in her master's degree; and her doctoral study's focus on educational leadership and policy analysis. She had been a high school teacher before she joined the university as a faculty. She played a proactive role in launching the Vietnamese Dual Language Program at her institution and then deeply involved herself in community engaging by closely working with stakeholders to facilitate the process of establishing a national resource center for Asian languages. Her great contributions made her promoted to the director post of this center. Her center offered the language teaching programs in Vietnamese, Chinese, Korean, and Japanese and on the way to additionally Khmer to serve Cambodian community in California. She described her pathway to the leadership as a department chair as follows;

I was a coordinator for Doctoral program for two or three years I think
and I am interim Department and then this opportunity become open to
serve a Department Chair for another department actually the
Secondary [Education]. So, I was in Educational Leadership
Department. But when the opportunity to serve as a capacity. I took that
opportunity. So, this is my second year serving as Department Chair
for Department Education. (Interview Transcript of Case 3)

Case 4 - Nadia. Nadia had an educational pipeline and many points of her pathway to academic leadership which were almost the same as the first and second cases of Claire and Ruth. She was originally from Taiwan. She held B.A. in Physics in Taiwan and took a graduate program directly to the Ph.D. program in Physics in high-profiled university in the U.S. She was a professor of Physics at a research university in California. At the time of the interview, she was Co-Director of a nanoscience research center of her university and a senior research team leader for many years. Compared to the other cases, Nadia had much more advantages in her educational and work experience pathway to her current academic leadership post. Through her story, it could be inferred that her mother and her academic advisor for her graduate study played the biggest roles in her educational and professional pathways. No matter how rare it was to have woman as scientists in the Physics field both in her country and the U.S., her mother and her academic advisor did transcend minority self-perception on their career. She shared; 
When I was growing up, I've never felt that women couldn't do things than men do because my mother was a mathematics professor in Taiwan. And also I grew up like always very accomplished academically and I looked at my mother, so I never felt that I couldn't do things. But I decided to study physics when I was only 12. I've already had this decision and I focused on it. And then I was lucky coming to the US, then I joined Professor'[name] group...I joined her group and she was very distinguished very well-known and so I never felt that women couldn't do thing because I have this mother and I have this advisor". They were both women and they were doing just fine. So I've never felt there are any problems until actually when I went to academic career myself that I realize "Oh actually there could be issue! (Interview transcript of Case 4).

\section{Cross-Cases}

The four cases revealed many convergences in their demographics and pathway to their academic leadership posts. First, all of them are from middle-class families in their original societies. Either of their parents worked in the field of education. Although they were from Asian families who commonly forced their children to pursue academic majors of high demand in labor market and high respect in contemporary society, they were free to choose profession of their own strength and passion. Second, all of them had high academic achievements at high school level. Third, all of them took graduate studies in the U.S. except for the third case with the pseudo name Nancy who studied in the US from K-12 level. Fourth, three of them were the first generation of their families in the U.S. and one of them is 1.5 generation. Fifth, all of them have been in the U.S. for more than 20 years. The case Nadia was the most striking case with 35 years of experiencing life and profession in the U.S. Lastly, they moved up to academic leadership positions when they had been married except for Nadia. She was the only case who was still single at the interview time. She insisted that she would like to maintain this single marital status in order to focus her entire mind and energy for the science career she has been devoted for long. Examining leadership pathways of the four cases highlighted that the factors of class featured by their family background (middle class) and role model from their parents and academic advisor took big roles in their success in the academy. Moreover, the multiple success case study data implied that their self-efficacy denoted by their confidence in choosing their own majors to pursue in graduate studies in a country [U.S.] very much far away from their home countries was another decisive factor of their success in the academy.

\section{Identities and Elements Influencing AAW's Leadership Pathways and Practices}

The analysis of interview data on NVivo informed that there were seven identities and elements related to individual and institutional aspects influencing and shaping AAW in academic leadership. They included (1) gender, (2) race/ethnicity, (3) class, (4) culture, (5) institutional cultures, (6) role model, and (7) others. Table 3 below discloses that among these seven identities and elements, institutional cultures and gender were mentioned the most by the participants. Individually, Claire shared the most about her institution with 31 references while Ruth and Nadia did almost the same (15 and 14 references respectively). Both Claire and Ruth shared a lot about their gender and how much they perceived it influenced their leadership. However, Claire said very little about her family while Ruth did much about her family and Asian culture which contributed to her leadership pathway and practice. Nancy more 
emphasized her gender role than other factors. Nadia gave a lot of information on her institution and how it made her devoted to it for long.

Table 3

\begin{tabular}{lccccccc}
\multicolumn{6}{l}{ Weight $*$ of Influencing and Shaping Identities and Elements } & (Analytical Results from Nvivo 12) \\
\hline Case & $\begin{array}{c}\text { Gende } \\
\text { r }\end{array}$ & $\begin{array}{c}\text { Race/ } \\
\text { Ethnicity }\end{array}$ & Class & Culture & $\begin{array}{c}\text { Institution } \\
\text { al Cultures }\end{array}$ & $\begin{array}{c}\text { Role } \\
\text { Model }\end{array}$ & $\begin{array}{c}\text { Other } \\
\text { Elements }\end{array}$ \\
\hline Case 1- Claire & 9 & 4 & 1 & 7 & 31 & 6 & 0 \\
Case 2 - Ruth & 9 & 6 & 4 & 5 & 15 & 1 & 0 \\
Case 3 - Nancy & 6 & 3 & 2 & 2 & 3 & 2 & 1 \\
Case 4- Nadia & 7 & 2 & 1 & 1 & 14 & 3 & 0 \\
\hline
\end{tabular}

* Measured by numbers of references (participants' quotes) counted through two coding stages.

The most interesting finding was that the institutional cultures accounted for the biggest number of references in the data analysis on Nvivo (63/145 or $43 \%$ ) while gender made up the second biggest with 31 references or $21 \%$ of the total references.

\section{Gender}

Gender was a social identity all four participants touched in their stories. They talked about gender in the aspects of their gender role at work and in family. They also shared their own perceptions of the way in which gender stereotype affected them in workplace.

Nancy's story as an example. What she shared about her gender role at work and in family and leadership characteristics had many things in common with the other three "story tellers". In the first "hat" of leadership at the Secondary Education Department, Nancy was not in the minority in terms of gender, but she was in the position of director of the language center. Under her supervision at this new department, there were 15 full time faculty and between 30 and 40 part-time faculty. The gender in her department was predominantly female.

Like many other working women, Nancy was also a mother. She has two children (3 and 5 years old). Dual functions as a female leader and as a mother challenged her in balancing her time and energy for work and family. She disclosed;
It's hard... We have 24 hours in a day and more and more work you know and workload has increased and the speed that we have to respond to the speed we have to act. [For example], people send out email and they expect you to respond within you know [laughing] 24 hours is not...So it's difficult and I did not realize the depth of difficulty until I was in this role. You know until I have an own family I know how I have to say profound appreciation for working women and for working moms" (Interview Transcript of Case 3).

She also implied that during the course of work-family balance, she had to refuse or prevent herself from attending a lot of events scheduled in the evening or at weekend. This could be inferred that compared to male counterparts, female leaders are inferior in their social networking. In fact, no one in their family inhibited them to get out for social events at night or at weekend, but their conscience of their gendered role as a wife and a mother made them limit their time for outside activities. This point was specifically shared by Ruth, "We [her department] have the evening events - all the cocktails, breakfast series. Everything, so hard [for her to join]! (Interview Transcript of Case 2). Also as a mother of a boy, Ruth faced the same challenges as Nancy in balancing time and energy for work and family: 
It's hard. And my job does involve a lot of weekend and evening we [her department] teach on the weekend. We teach in the evening...I really don't feel like ... We choose work for many many hours but at least I have flexibility, but I feel I don't work until my son goes to bed, then I continue work. (Interview Transcript of Case 2).

Both Nancy's and Ruth's stories informed that although their husbands helped them a lot in taking care of their children, as mothers, they felt they needed to spend more time for their children when they were small (under 8 years old).

What Ruth and Nancy shared could imply that women's high sense of responsibility for work and family got them under "the double burden" of work at work and work at home as the sociologist Hocheschild (1997) terms in The Time Bind (p. 651). It was evident that social and cultural norms, and women sense of responsibility have shaped their thinking and behavior as mothers necessarily close to the children, especially when their children are small; and as working women to fulfill assignments at work.

\section{Race/Ethnicity}

The analysis of data showed that race referred to the participants' perception on their identities as Asians, stereotype and assumption of surrounding people on their behavior and personalities applied in their leadership practice, and their responses to such stereotype and assumption. In addition to gender factor, all the participants were aware of their own Asian identity as a minority in their institutions. They were also aware of the stereotype and assumption the others surrounding assigned to their behavior and personalities.

Once being asked if she have ever felt herself "minority" in her voice when working as a female Asian leader in her institution, Nancy replied;

The stereotypes of race of Asians and Asian Americans [often tend the
myth that] they [female Asians at work] are not threatening, they are
not assertive and sometimes because they are not assertive and they are
not always the loudest room, the loud voice in the room, that maybe
there not competent for their not engaged or you're [perceived to be]
very permissive or very obedient" (Interview Transcript of Case 3).

In her leadership role, as an Asian, Nancy also affirmed her clear awareness of her race and she viewed it as a value she has embraced and did not intend to abandon or assimilate it into the mainstream race in her work place although the stereotype about Asians sometimes made her feel uneasy. She shared what she has been striving to do in her leadership would make people not connect such a stereotype to her racial image. Her success story in the academy provided a big recommendation for Asian females to be rationally confident in their own racial status and to consider it as a special value that make them positively distinctive in their leadership. She also provided that people of the mainstream race and gender might first stereotype Asian female leader, but the leadership capacity and efficiency of the latter could change initial assumption of other people on their behavior and personality. Eventually, they might not pertain minority race to leadership efficiency. Agreeing with Nancy, Ruth also viewed her Asian identity as her own unique feature worth preserving. However, she suggested in leadership practice, Asians need to understand the other racial identities in order to have most appropriate leadership style and behavior. She recommended to learn how to read the mind of the Americans.

Summing up, all the four success cases have experienced stereotype and assumption of other people on their personality and behavior (permissive, quiet, unassertive to the few) which 
were thought not bring about effective leadership. In order to transcend such stereotype and assumption all of them agreed with each other in their strategies of preserving their Asian identity and regarding it as a positively distinctive feature. As Asian women, they quietly tried their best efforts to enhance their profession and integrate their own Asian characteristics strengths into good mainstream's personality for the sake of institutional achievement. For example, Asian woman leaders should be more open for straightforward conversation with others, more strongly say "No" to the assignments from the upper authority if they feel overwhelmed with current responsibilities. This mean they should negotiate their work assignments.

\section{Class}

Class identity in this study refers to the participant's family backgrounds, mainly their parents (their jobs, their expectations and influence on their children's educational and job choices). As mentioned in the findings of demographics and pathways of the success cases to academic leadership, all the participants except for Nancy were from middle-class families.

Claire (Case 1) came from the family with high expectations for her academic achievement although her parents did not influence her academic major and job choice. The way her parents, particularly her mother, led the family gave her good lesson of leadership. She proudly shared, "She [Claire's mother] was working for other people. She started her own company. She worked by herself. She was very independent. And it was very unusual in the 1970s in Hong Kong" (Interview Transcript of Case 1)

Ruth (Case 2) was different from Claire in the point that Ruth's educational pipeline was impacted by her father rather her mother. Her father worked in education, not in business as Claire's mother. Ruth did not mention much about how her father influenced her leadership characteristics. However, her story implied that both her father and mother supported her further studies in the US although they were not pleased with her professional choices of psychology, information science and business administration.

Nancy's journey to the U.S. and leadership was quite different from Claire and Ruth. She did not have good advantage in her family background. But she was blessed with a wonderful mother. When coming to the U.S., her mother enrolled in a community college. She got a degree and she became a successful nurse. The difficult and successful life as well the resilience of her mother did inspire Nancy to do her best to become a good student and then a teacher in the U.S. Like Claire's and Ruth's family, Nancy's mother did not press her into major and career of her will. Her mother did respect Nancy's own passion for education field and career.

Nadia's family background was similar to Claire and Ruth, but the way they influenced her educational pipeline and work experience was much explicit and stronger as quoted in CaseBy-Case presentation above about the pathway to leadership.

In conclusion, there were two most striking findings regarding class identity influencing and shaping their leadership pathways and practices. First, they were generally from middleclass family, meaning they received good investment into their education in terms of finance (except for Nancy) and embraced motivation. Second, they were free to pursue their own professional passion. This could rationally explain for their professional success. Many studies prove that passion, self-efficacy, and motivation are among crucial elements constituting success of education and career (Bandura, 1986, 1997; Michaelides, 2008; Schunk et al., 2008; Usher \& Pajares, 2009). 


\section{Culture}

Culture referred to the way the participants interpreted about their leadership and the counterparts' leadership under the influence of culture. All the four cases in my study were born and grew up in their home countries in China (Hong Kong and Taiwan) and Vietnam, I hypothesized their leadership was deeply influenced by Asian culture under strong impact of Confucianism embracing in-group collectivism, institutional collectivism, and performance orientation. In-group collectivism is featured by the expression of pride, loyalty, and cohesion in their organizations and the leader is devoted to their organization. Institutional collectivism is associated with "broader societal interests rather than with individual goals and accomplishments" (Northouse, 2016b, p. 432). Group cohesion and loyalty is thus highly expected. Performance orientation emphasizes encouragement and rewards given to group members for improvement or excellence in their performance.

Claire admitted that under the impact of Asian culture, her leadership was more collectivistic. Group good was her priority. She thus felt hard to refuse further jobs assigned to her although she had been already overwhelmed by current responsibilities. Claire also shared she confronted the conflict between the culture in which she was raised and grew up with and the culture in which she worked. The former was Asian culture of high expectation from parents for her academic achievements. Negative feedbacks from teachers and parents for improvement was widely considered as a good way to encourage children and students for better efforts. The latter is American culture in which giving a straightly negative feedback to children and students is believed to discourage their efforts for improvement.

Ruth (Case 2) also confided a lot of things related to culture. She was fully aware of differences in Asian and Western cultures and she tried her best to accommodate them well in her leadership practice. She articulated in Asian culture, parents valued education for young people. In their mind, education was a "passport" for good future marriage for girls and successful future career for boys. She also highlighted that in Asian culture, students were not customers. Asian leaders could push employees to work hard by telling them the job is hard hard job in Asian culture is as a push-up. It is quite different in the US where students are considered as customers. They should be served, not commanded to work hard for scores. It is the same in work. Leaders in American culture would discourage their followers if they said beforehand the jobs were hard - a hard job as a pull-down. They were expected to encourage the subordinates to go ahead rather than challenge them with hard jobs to do.

Ruth's story provided big lessons for other Asian people to work smoothly in American culture. She highlighted the distinctions between Asian and American culture and from her practice. She recommended that Asians should get insights into American culture. That is, learning about their culture for better understanding and then adapt Asian culture wisely in their leadership without losing their Asian identities. Nancy had the same interpretation on her leadership behavior as Claire - more collectivism, harmony for group benefit, and no selfpromotion.

Nadia like Claire, Ruth, and Nancy were fully aware of good points and not-good points [in American context] of Asian culture in which they were raised and grew up. She critically claimed,

That's kind of our culture that is kind of disadvantage, but over time I mean I did run into the people, people who knew me, people got to know me and recognized me and eventually it works out but I would say I am thinking in general because of culture and gender differences in terms of how we approach things, how we insert ourselves. Women and Asia people may be people on the like of disadvantage, but things are improving and also given time I think the recognition was coming 
eventually. It's that they may not say, certain recognition could not have been given sooner. But they've come a little later. It is because of type of cultural issues and behavior issues (Interview transcript of Case 4).

Generally, all of the participants in the study were fully aware of key differences of Asian culture in which they were raised and brought up from American culture in which they interacted with at work in the U.S. The most remarkable that they realized positive points of Asian culture to be strengthened such as collectivism for institutional goals, hard-working without loud voice about their contributions; and harmony in their decision-making, which helps institutions be away from possible internal conflicts. Meanwhile, they perceived they should adjust their own Asian culture to American culture in order to get everything to go smoothly toward institutional achievements. For example, they first learned "how to read American minds" (Interview transcript of Case 2), then to be open for straight conversation. They understood that they should be more self-promoting and negotiating their assigned responsibilities. In the way of giving feedback, they knew how to give positive feedback to encourage the team members to be confident to go ahead. For subordinates with not-good performance, they managed most relevant way to imply them to correct and improved by themselves.

\section{Institutional Cultures}

Institutional cultures in my study pertained to institutional history, demographics, specific values and policies that distinguished the institutions of the participants from those of the others. The data analysis revealed that some of the participants were supported by leadership development program offered by their institutions while the other participants shared their institutional policy regarding tenure and overloading work discouraged them. Both Claire's, Ruth's and Nadia's institutions shared the same features of their small private universities, which nurtured close communication across the campus, particularly professional exchanges. Claire was very proud of long history of her university serving women. In addition, values of equity and equality in benefits, professional development, and promotion opportunities without acute competition were also elements which made her retain in her institution for long. Ruth shared the same positive feeling about her institution as Claire in terms of female institutional history. Both of them did not feel minority in their voices. However, both Claire and Ruth did not like the way their institutions assigned them bigger service workload in compared to other larger-scaled universities. No-tenure track available was another point they felt discouraged about their institutions.

For Nancy, "diversity" was the key word she used to describe her institution. It referred to student body, faculty, culture, ethnicity and academic programs. It influenced not only her perspectives but also view of other people on their institutional culture. The values of tolerance, social responsibility, innovation, and creativity were thus embraced in her collegial community. Nancy also expected her institution to be more supportive by providing leadership development programs as she had attended in the past. She wanted this kind of program to be offered to "emerging leaders" because "in any higher education institution it is constantly changing, some of these are political, some are of these policies, so there are a lot of movements" (Interview Transcript of Case 3). She affirmed her goal was to continue to contribute to and serve her university. She considered the institutional goal as her individual goal.

Nadia's story on her institution was quite different from the other three cases. She first loved her small nice campus in which professional exchange and communication went dynamically and smoothly across the institution. She also felt supported to pursue knowledge generation through research projects and academic and research excellence. Treating faculty fair and comparable pay offered were the other two elements keeping her and other peers 
devoted to the institution for long. She highly appreciated the way the senior administrators listened to professors because most of them were promoted from academic positions. Last but not least, tenure track was available for all faculty. It went fast for those who were truly competent in academics and research. Generally, the institutional cultures and policies in her mind and eyes were so good and satisfactory that she did not pay any attention to them. She could focus her entire mind and energy on her research leading responsibilities.

In summary, what the participants shared during the interviews illuminated some institutional cultures perceived as facilitators for their leadership development. They included institutional support for academic and research excellence; diversity in student and faculty bodies and in academic programs; equity and equality in benefits, professional development and promotion; small campus for close cross-campus exchanges; respect for faculty voice in decision-making; and tenure track availability. It is noteworthy that while Claire and Ruth were satisfied with their minority serving institutions and small-scaled campuses, they felt discouraged by tons of trivial responsibilities assigned to them and limited tenure track offered.

\section{Role Model}

Role model was an emerging element in my data analysis, but it was worthy noticing because all of four participants mentioned about their own role models, who greatly contributed to their current success in academic leadership. Claire and Nancy shared most about their mothers; Claire about her former and current supervisors while Ruth mentioned very generally about her role models. Nadia talked very specifically about her mother as well as her academic advisor of her graduate studies. Claire had three role models shaping her leadership pathway and practice - first her former supervisor, second her current dean as good examples of competence in working across differences and conflicts; and third her mother as a businesswoman. Nancy's story highlighted the role model of her mother who escaped Vietnam in early 1980s in a small boat to the US, pursued study at a community college, did two jobs to feed her family life. The resilience, strength, courage, caring for family, and child education of her mother had set a role model for Nancy to follow to be successful as she desired for. She perceived the resilience, loving and caring of her mother were rather typical characteristics which could be found in most of Vietnamese women. But the unique features of her mother were knowledge-inquiring and respect for children's choice of education and profession.

As a successful professor and research team leader in physics, Nadia was grateful for her academic advisor in her academic and research excellence as well as her competence in establishing and developing work-team in research projects. Nadia's story also revealed that her strong personality as a competent and devoted scientist was inherited from her mother who was a mathematics professor as a phenomenon in Taiwan in her mother's time.

In spite of emerging node in the data analysis, the role model was significant in many aspects. First, the participants' pathways to academic leadership and their leadership practices were strongly influenced by their role models as mothers, academic advisors, and job supervisors. Those models provided them with robust financial and mental supports for their journey from education to profession and leadership. Second, all of their role models were mentally strong, self-confident and independent women. It is definitely like "women help women well". They enabled the participants to transcend their own barriers of gender, race, and culture, and develop in new competitive contexts in the U.S.

\section{Other Elements}

There was another emergent element in my data analysis. I was not sure which node would adequately accommodate it, so I decided to put it as a separate node in NVivo. It was the sense of belonging to religion. In spite of not being asked about religion, Nancy intentionally 
disclosed, "I am a Buddhist and I have been got trained as much as early age about the importance of harmony within a group and I think it is probably because of Asian culture as well" (Interview transcript of Case 4)

\section{Other Significant Findings}

The parent node "Others" on NVivo was for further perceptions of the participants on their leadership pathways and practices shared at the end of the interviews. It was as about career vision they had had before going to the U.S. for further studies, about American values instilled in the academy in the U.S. I found this node remarkable in the way which could imply me additional angles for my future research focus on national and institutional culture, value, and policy - which one(s) encouraged and which one(s) discouraged AAW in their leadership in American academic context.

All of them disclosed the same feeling of being unclear about career vision when they first came to the U.S. It is understandable because at that time - over 20 or 30 years ago - they were too young to envision their future career although they had serious attitude and good efforts for their graduate studies.

I could say Nadia's story was the most impressive. She experienced life, study, and work in the U.S. for over 35 years - much longer than the other three participants. It is thus rational to assume her perception on American academia was the deepest and fullest. She contended that her academic and professional journey to the U.S. was an inspiring and rewarding exploration. She highly appreciated the American institutional cultures of meritbased reward and equality for opportunities to move up in professional ladder for those who worked hard for their passion. Her story also informed that American academia and American society are open chance for prestigious scientists like her to greatly contribute to areas beyond her institutional boundary. She enjoyed devoting to national and international policies related to areas beyond her narrow profession in physics. She felt her broad vision and competence for cross-disciplinary issues were heard and respected.

Ruth's story was also striking. She worked hard to change her academic majors for a couple of times. And she successfully completed academic programs from psychology, information science to business. She was thankful for the flexible policy of American higher education which open for students like her to try their passion in different areas during their educational journeys. Other things she liked about American values in compared to Asian societies were less discrimination against women, more tolerance toward people of different colors and origins. She also liked the way people in the U.S. are generally straightforward in communication and more open to listen to others in discussion to seek best solutions.

These emerging findings were valued in the meaning that they could provide implications for reasons why the participants in my study have retained and developed well in academia in the U.S.

\section{Preliminary Intersection Model of Identities and Elements Influencing and Shaping AAW's Leadership Pathways and Practices}

Last but not least, the findings of this study together with intersectionality concept could inform a preliminary intersection model of identities and elements influencing and shaping AAW women leadership. I fully understood that only four success stories were not robust enough to formulate an intersection model. But through the coding and analyzing procedure conducted on NVivo, at least the study could provide evidence to map out a preliminary intersection model. To expose the nuance of data analysis on the interplay of the identities of gender, race, class, culture, religion, institutional cultures, and element of role model; the function of word search query on NVivo was commanded. The word trees (Figure 3-8) below 
were the outcomes of word query, which elicited the following notions of intersectionality of identities and elements shaping AAW's leadership pathways and practices:

- Gender, race, and culture tremendously intersected to influence and shape AAW's leadership in the U.S. higher education (please see textual evidence in Figure 3 and 4);

- Class of family also interacted with gender in which mother played an important role in the leadership pathways and characteristics of AAW (textual evidence in Figure 5);

- Institution, cultures, and gender (women) also intersected to impact and shape their leadership practices (textual evidence in Figure 6 and 7);

- Role model was expected to intersect with gender (mother and female supervisor), but the data analysis on NVivo did not show any evidence for interaction of role model with any other identities and elements (textual evidence in Figure 8).

- Religion: outlier identity, did not interplay with other identities and elements, but could be inferred to be close to culture based on the quote of a participant.

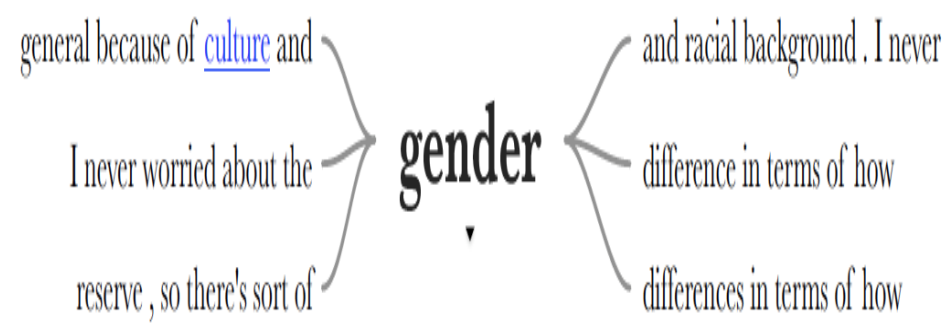

Figure 3. Interaction of Gender and Culture

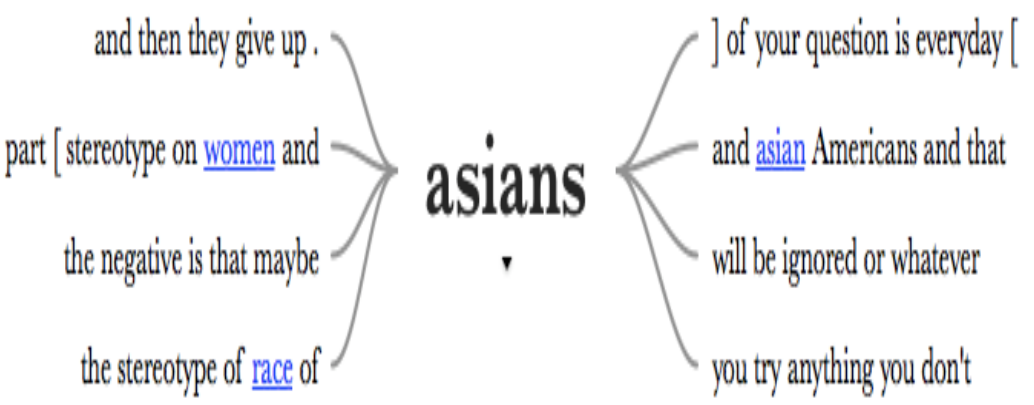

Figure 4. Interaction of Race and Gender 


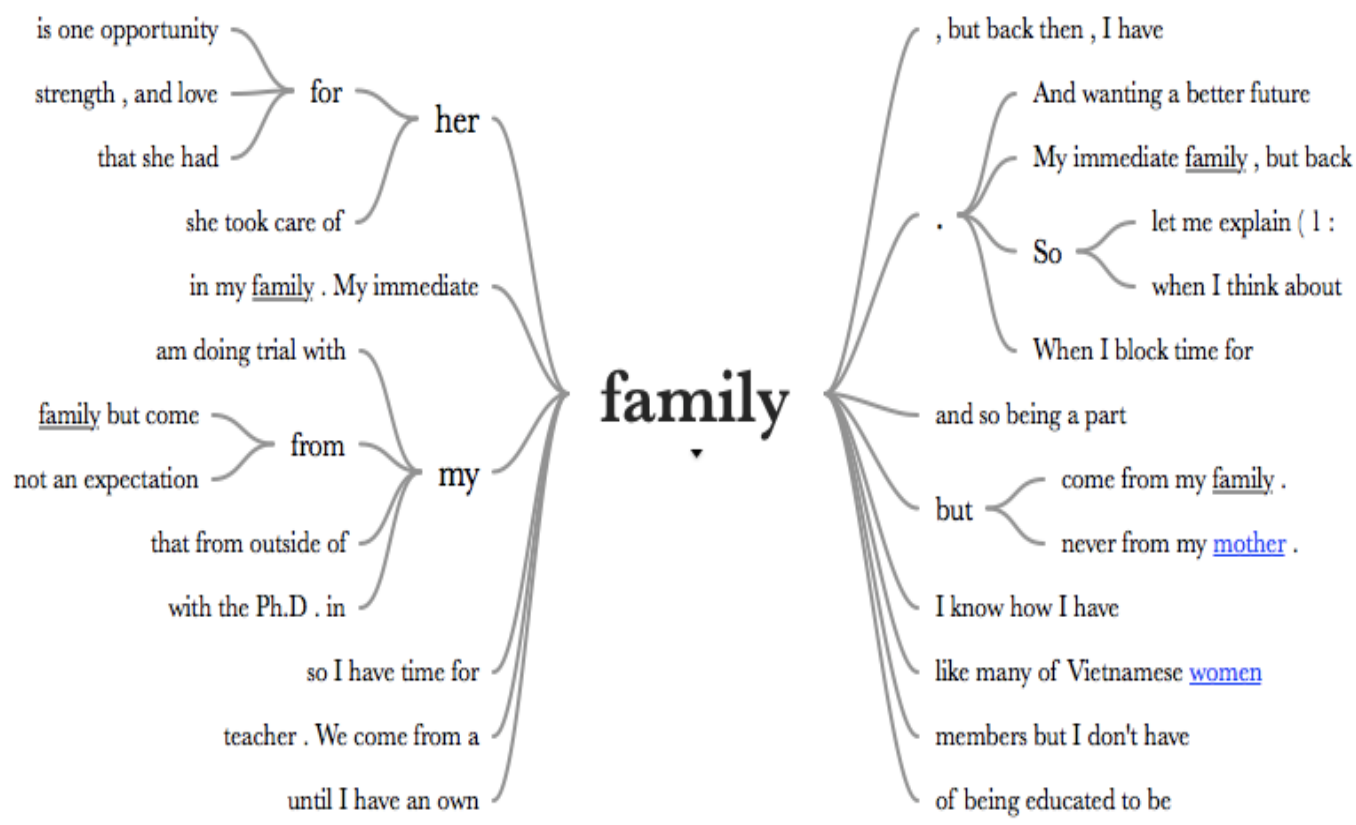

Figure 5. Interaction Between Family (class) and Gender

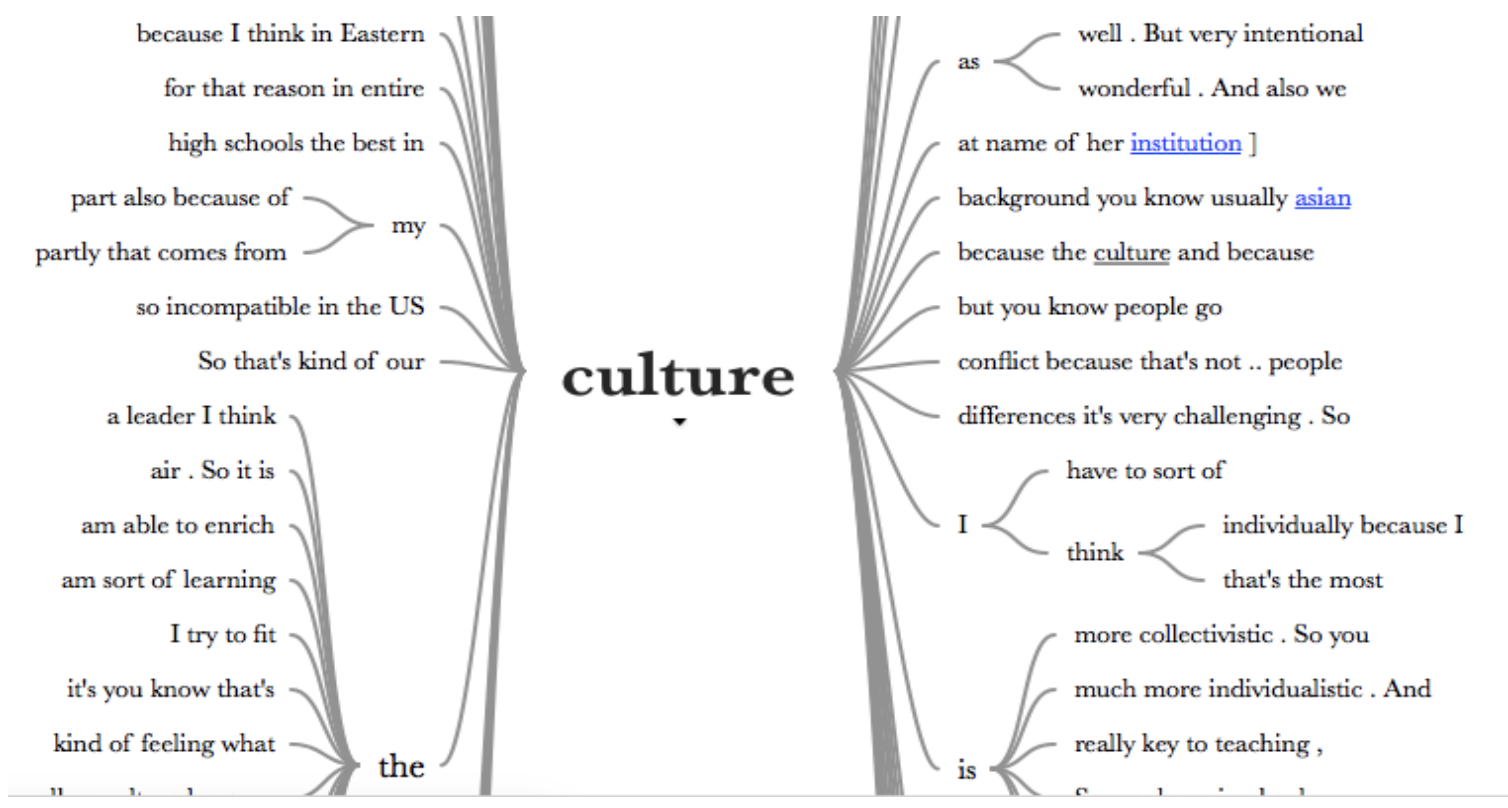

Figure 6. Interaction of Culture, Race and Institution 


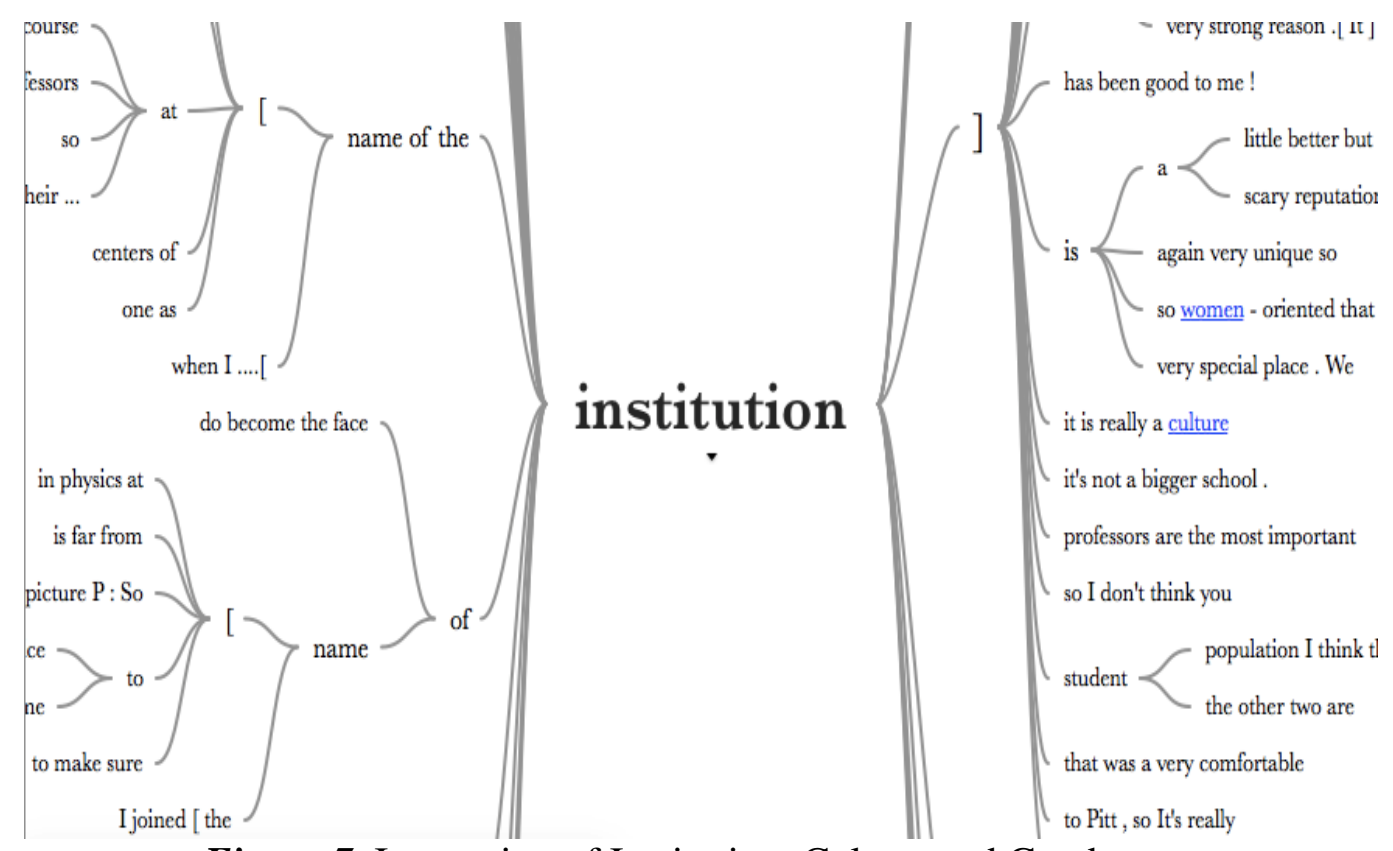

Figure 7. Interaction of Institution, Culture and Gender

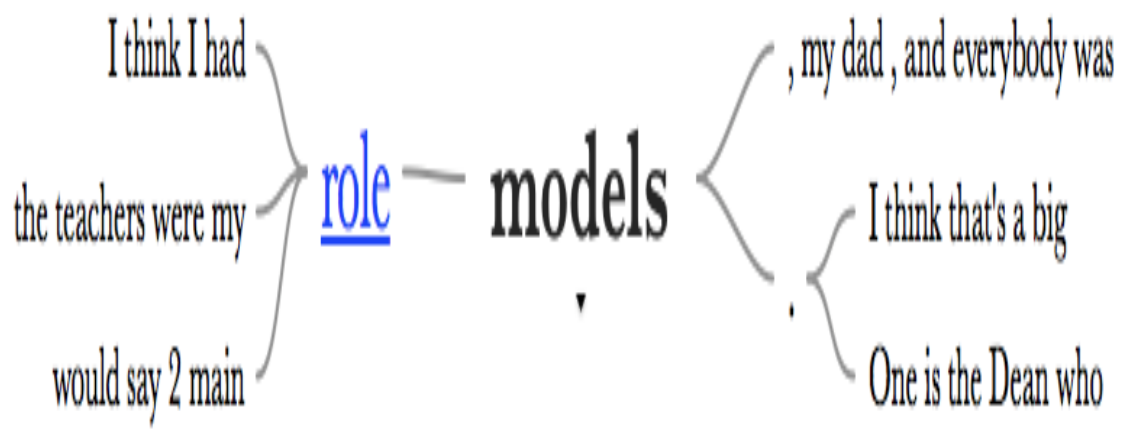

Figure 8. Role Model

The word trees above and weight of identities and elements presented Table 2 and 3 in the Findings provided evidence to map out a preliminary intersection model as visualized in Figure 9 below. The size of each circle represents for the weight or strength of identities/elements influencing and shaping AAW's leadership labyrinths and practices. The proximity and overlapping between circles informs how much (the degree) each of the identities/elements intersected with the others. 


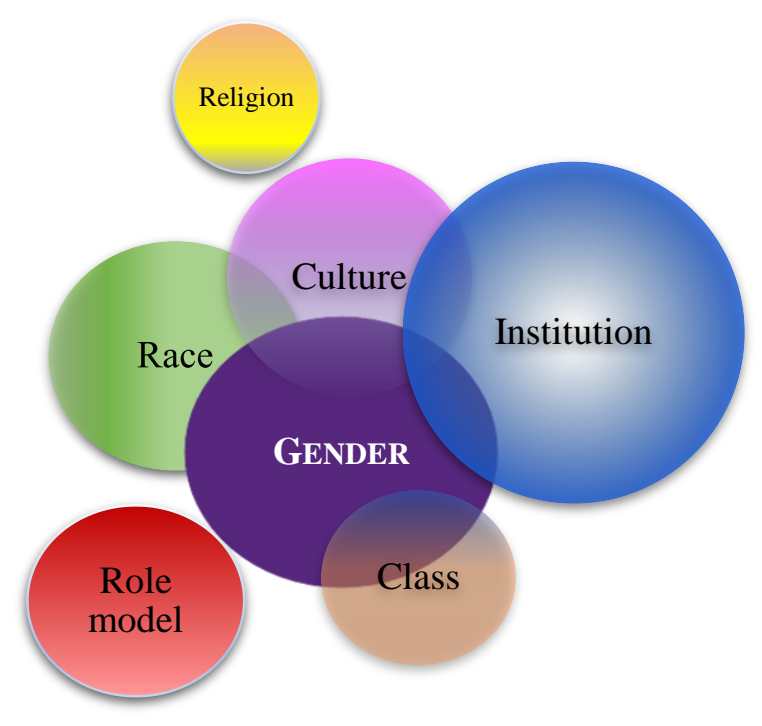

Figure 9. Preliminary Intersection Model of Identities and Elements Influencing and Shaping AAW's Leadership Pathways and Practices in Academe

Besides the notions drawn from the word search query above, the preliminary intersection model presented in Figure 9 could further imply that:

- Gender was the centered social identity intersecting with almost all other identities and elements (race, culture, class, and institutions) to impact and shaping AAW's leadership trajectories and practices.

- Institutional cultures were the strongest, interplaying with some of the other identities (gender and culture) to facilitate success of AAW's paths to leadership.

- Race and culture had the same strength, but were different in the way they intertwined with the other factors. Race directly interacted with culture and gender while culture with race, gender, and institution.

- Role model was very close to gender, but not connected to the other factors although participants' quotes implied some association with family class through mother's role and institution.

- Religion was an outlier element, and it was close to culture.

\section{Discussion of the Study's Contributions and Limitations}

The study illuminated the similarities and distinctions in the pathways to academic leadership of AAW success cases. Most of them had the same educational pipeline - pursuing graduate studies in the U.S. (both Masters' and Ph.D. degrees), then moving up to academic advancement from lower to higher leading posts. The pipeline of their graduate education and professional development toward leadership took twenty years on average. And most of them were from middle-class families, which could be considered as their socio-economic advantages for their strong education and profession to academic leadership in the academy. However, the study could not figure out straightly why they chose the U.S. academy as their professional destination rather than other countries of the same advanced higher education system even though at the end of the interviews they listed out a series of good points of American academic policy across the U.S. They perceived higher education institutions in the U.S. generally flexible in allowing students to switch their majors per their changing 
professional interests. Society and institutions were viewed more welcoming and more respect for differences. The U.S. legal system has been increasingly protected justice and equality for every citizen regardless race, gender, culture, and faith although people of color and women has still faced persistent invisible barriers. It should be noted that such perceptions of the participants on American institutional cultures and society had not been mentioned for their choice of the U.S. as their professional destination until they anchored their career in American academia. Their self-disclosure of unclear vision for their future career before they came to the U.S. could make an inference that the choice of the U.S. for their graduate studies was decided by their parents rather than by themselves although they were free to pursue their own majors of their best passion.

The pathways of the four cases to academic leadership positions in my study were generally consistent with previous studies (Kawahara, 2007; Kawahara et al., 2007; Kawahara et al., 2013; Kawahara et al., 2020) despite the subjects in these studies included AAW women in both academic and administrative posts. Differently, there was one case (Nancy) of my study who did not have the same advantageous socio-economic status as the other three cases did. This different case was found similar to the case in Chin's (2020) study - moving up from "an immigrant, working class family to becoming a psychologist, executive director, health care administrators, scholar, and academic dean" (p. 182).

In terms of identities and elements influencing and shaping AAW's leadership labyrinths and experiences. My study consolidated the notion of prior studies (Chen \& Hune, 2011; Chin, 2020; Hune, 1997, 2006, 2020b; Kawahara, 2007; Kawahara et al., 2013; Liang \& Peter-Hawkins, 2017; Loo \& Ho, 2006) that AAW's trajectories to leadership regardless of academic or non-academic posts and in higher education or K-12 education were manifested by "intersected experiences of gender, race-ethnicity, and age, situated in particular time and place" (Liang et al., 2016, p. 623).

In order to seek personal strengths contributing to AAW women's success in academic leadership, my study found similar characters revealed by other studies of Asher (2010), Kawahara (2007), Kawahara et al. (2020), and Kawahara and Chin (2013). The distinctive characteristics of the success cases included resiliency, self-empowerment by best efforts in professional development, pride and confidence in personal identities. In terms of institutional cultures, the findings of this research confirmed the findings of the previous studies of Asher (2010), Chin (2020), Hune (2006), Kawahara (2007), Kawahara et al. (2020), Liang et al. (2016), Nguyen et al (2018), and Wu and Ida (2018). Generating and nurturing diversity in all aspects of institutional activities, providing encouragement and mentorship to AAW potential for leadership, and promoting equal treatment in recruiting and promoting were key catalysts for their advancement toward leadership.

Together with the previous studies, my study highlighted specific strategy AAW applied to overcome the stereotypes and invisible barriers related to "bi-culturalism" as Kawahara (2007) conceptualized in her study. AAW's full awareness of fundamental differences between Asian culture in which they were raised and grew up, and American culture in which they interacted with at work in the U.S. made them obtain bicultural efficacy. They were capable of learning ways to adapt their own Asian culture to American culture in order to get things done for institutional performance. They wisely integrated strong points of Asian culture such as collectivism for institutional goals, hard-working without loud voice about their achievements and contributions; and harmony in their decision-making into American culture context. They were confident to claim that such a cultural integration did enable them to lead their organizations away from possible internal conflicts. They successfully learned "how to read American minds" (Interview transcript of Case 2), then to be open for straight conversation with the other members in their organizations.

One of remarkable findings in my study regarded to parents' respect for children's choice of major; which had been rarely emphasized by previous studies. The parents of the 
participants did not press their children to careers of high demand and social profile in contemporary labor market and society respectively. AAW leaders in my study were free to pursue their own professional passion, not dependent on their parents' influence like other Asian families in their home societies. This could rationally explain for their professional success. Many studies in other areas than AAW and leadership prove that passion, self-efficacy, and motivation are among crucial elements constituting success of education and career (Bandura, 1986, 1997; Michaelides, 2008; Schunk et al., 2008; Usher \& Pajares, 2009).

The most striking of this study was the preliminary intersection model of identities and elements influencing and shaping AAW's leadership pathways and practices, which evidently depicted which identities/elements were closely or loosely interacted with the others. The findings proved that gender, race, and culture tremendously intersected to shape AAW's leadership in American higher education. Class of family also interacted with gender in which mother played an important role in the leadership pathways and characteristics of AAW. Institutional cultures, personal cultures, and gender (women) also intersected to influence and shape their leadership practices. Role model intersected with gender (mother, and female academic and work supervisors), which was proved by qualitative evident (sense of quotes), not by quantitative evidence (occurrence number of words/quotes directly denoting gender). Religion as an outlier identity did not interplay with other identities and elements, but found close to culture through sharing of a participant.

In terms of research methods, the study consolidated the "legacy" of the most influential trend in the research area of AAW and leadership. It was qualitative research method with evidence drawn from in-depth semi-structured interviews to obtain success stories of AAW in academic leadership. Furthermore, given a paucity of published research studies on AAW and leadership using Nvivo 12 in data management, analysis, and presentation for better visualization of the results; my study could imply for an alternative tool well serving qualitative research.

And given little research on leadership experience of AAW and limited scholarly works following the approach of diversity leadership model under intersectionality concept (Chin, 2013; Kawahara et al., 2013; Liang \& Peters-Hawkins, 2017); my study contributed to enriching the existing literature on women and leadership in general, and on AAW and leadership in particular under the novel approach.

My study was challenged by three key limitations. First, the sample size was small (only four cases). Second, there was lack of triangulation in data sources (only from interviews). And third, the preliminary intersection model of identities and elements relied solely on word search function of NVivo and coding results. These constraints definitely made my study restricted in external validity and reliability.

\section{Implications for Further Study and Conclusion}

As mentioned in the Discussion, in order to obtain more valid and reliable findings to consolidate and enrich the established knowledge generated by previous research studies on academic leadership labyrinth of AAW in American higher education, further study is needed with a bigger sample size from more AAW leaders originally from a wider range of ethnicity from Confucian societies (China, Korea, Japan, and Vietnam), and from different types and characteristics of higher education institutions across the U.S. Moreover, data sources should be diverse with interviews, documents, and observations to enhance trustworthiness of the study. Moreover, the preliminary interaction model of identities and elements should be developed to be more rigorous and robust model based on more trustworthy evidence from both qualitative and quantitative data sources.

In spite of some limitations noted above, the study contributed to strengthening the findings of previous studies on AAW's leadership pathways and practices, which have been 
under the intersection of multiple identities and elements associated with gender, race, culture, class, role model, religion, and institutional cultures. The findings also enriched the existing literature with the preliminary intersection model of multiple identities/elements influencing and shaping leadership labyrinths and practices. This preliminary model could inform that the gender has still centered and mattered the most, and it interplayed with all other identities/elements. Although higher education institutions have made good progress against discrimination, they have been called for continued support for AAW and women of color to overcome invisible barriers particularly connected to gender and culture.

\section{Acknowledgements}

This paper is crystalized from the author's independent research project in her Ph.D. journey at the University of Pittsburgh (Pitt). The author is deeply thankful to Professors Maureen Porter, Maureen McClure, Jean Ferketish, Jennifer Russell, Laura Lovette, and Julie Beaulieu at Pitt for their invaluable feedback and suggestion during the design, implementation, and sectional report writing of the study. The author was also indebted to Professor Shirley Hune at the University of Washington, and Professor Dina Maramba at the Claremont Graduate University for their scholarly provision of ample literature sources on Asian American women and leadership. A high appreciation is extended to the two blind reviewers for their precious detailed comments and recommendations. Last but not least, without valued participation in the interviews of the four AAW academic leaders, this study could have not obtained the outcomes.

\section{Funding Details}

This work is not supported by any grant funding.

\section{Disclosure Statement}

This is to acknowledge that there is no conflict of financial interest or benefit that has arisen from the direct applications of this research.

\section{References}

AAUW. (2016). Barriers and bias: The status of women in leadership. American Association of University Women.

Asher, N. (2010). How does the postcolonial, feminist academic lead? A perspective from the U.S. South. International Journal of Leadership in Education, 13(1), 63-76.

Bakalar, B. (2017). Understanding the whole student: holistic multicultural education [Book Review]. Journal of Ethnic and Cultural Studies, 4(2), 96-98.

Bandara, W. (2006). Using NVivo as a research management tool: A case narrative. In A. Ruth, (Ed.) Proceedings of the 3rd International Conference on Qualitative Research in IT and IT in Qualitative Research (pp. 6-19). Institute for Integrated and Intelligent Systems, Australia.

Bandura, A. (1986). Social foundations of thought and action: A social cognitive theory. Prentice Hall.

Bandura, A. (1997). Self-efficacy: The exercise of control. WH Freeman/Times Books/ Henry Holt \& Co.

Becker, H. S. (1996). The epistemology of qualitative research. Ethnography and human development: Context and meaning in social inquiry, 53-71.

Bergquist, W. H., \& Pawlak, K. (2008). Engaging the six cultures of the academy. Jossey-Bass. 
Brinkerhoff, R. O. (2003). The success case method: Find out quickly what's working and what's not. Berrett-Koehler Publishers, Inc.

Chemers, M. M. (1997). An intergrative theory of leadership. Lawrence Erlbaum.

Chen, W. C., \& Hune, S. (2011). Asian American Pacific Islander women from Ph.D to campus president: Gains and leaks in the pipelines. Diversity in Higher Education, 10, 163-190.

Chi, M. T. H. (1997). Quantifying qualitative analyses of verbal data: A practical guide. Journal of the Learning Sciences, 6, 271-315.

Chin, J. L. (2012). Advancing through the ranks: Challenges and transformations. In H. Curtisboles, D. M. Adams, \& V. Jenkins-Monroe (Ed.), Making our voices heard: Women of color in academia (pp. 155-164). Nova Science Pub Inc.

Chin, J. L. (2020). Successfully navigating career paths. Women \& Therapy 43(1-2), 182-196. https//doi.org/10.1080/02703149.2019.1684677

Chin, J.L. (2013). Introduction: Special section in Asian American Leadership. Asian American Journal of Psychology, 4 (4), 235-239.

Crabtree, B., \& Miller, W. (Eds.). (1999). Doing Qualitative Research (2nd ed.). Sage.

Crenshaw, K. (1989). Demarginalizing the intersectionality of race and sex: A Black Feminist critique of antidiscrimination doctrine, feminist theory and antiracist politics. The University of Chicago Legal Forum, 140, 139-167.

Crenshaw, K. (1991). Mapping the margins: Intersectionality, violence against women of color. Standford Law Review, 43(6), 1241-1299.

Daniel, J. (2012). Choosing Between Non-probability Sampling and Probability Sampling. In Sampling Essentials: Practical Guidelines for Making Sampling Choices (pp. 66-80). Sage.

Eagly, A. H., \& Chin, J. L. (2010). Diversity and leadership in a changing world. American Psychologist, , 65(3), 216-224. http://dx.doi.org.pitt.idm.oclc.org/10.1037/a0018957

Eagly, A. H.; \& Carli, L. L. (2007). Through the labyrinth: The truth about how women become leaders. Havard Business School Press.

Espinosa, L. L., Turk, J. M., Taylor, M., \& Chessman, H. M. (2019). Race and Ethnicity in Higher Education: A Status Report. American Council on Education.

Gudykunst, W. B., \& Ting-Toomey, S. (1988). Culture and interpersonal communication. Thousand Oaks, CA: Sage.

Hochschild, A. R. (1997). The time bind - When work becomes home and home becomes work. New York: Henry Holt and Company, LLC.

Hoeffel, E. M., Rastogi, S., Kim, M. O., \& Shahid, H. (2012). The Asian Population: 2010 Census Briefs. https://www.census.gov/prod/cen2010/briefs/c2010br-11.pdf

House, R. J., Hanges, P. J., Javidan, M., Dorfman, P. W., \& Gupta, V. (Eds.). (2004). Culture, leadership, and organizations: The GLOBE study of 62 societies. Thousand Oaks, CA: Sage.

Hoyt, C. L., \& Simon, S. (2016). Gender and leadership. In P. Northouse (Ed.), Leadership Theory and practice (7th ed., pp. 397-426). Sage.

Huang, Guiyou. (2008). The Greenwood Encyclopedia of Asian American Literature, 1, 257261.

Hune, S. (1998). Pacific American women in higher education: Claiming visibility \& voices. Washington D.C.: Association of American Colleges and Universities.

Hune, S. (2002). Demographics and diversity of Asian American college students. In M. K. McEwen, C. M. Kodama, A. N. Alvarez, S. Lee, \& C. T. H. Liang (Eds.), Working with Asian American college students (pp. II-20). Jossey-Bass.

Hune, S. (2006). Asian Pacific American women and men in higher education: The contested spaces of their participation, persistence, and challenges as students, faculty, and administrator. In G. Li \& G. H. Beckett (Eds.), "Strangers" of the academy: Asian women scholars in higher education (pp. 15-35). Sterling, VA: Stylus Publishing, LLC. 
Hune, S. (2011) Asian American women faculty and the contested space of the classroom: Navigating student resistance and (re)claiming authority and their rightful place. In: Vol. 9. Diversity in Higher Education (pp. 307-335).

Hune, S. (2020a). Introduction: Our histories. In S. Hune \& G. Nomura (Eds.), Our voices, our histories (pp. 8-16). New York University Press.

Hune, S. (2020b). Prologue: Taking action: Asian American faculty against injustices in the academy. In K. L. C. Valverde \& W.M. Dariotis (Eds.), Fight the tower: Asian American women scholars' resistance and renewal in the academy. New Brunswick, NJ: Rutgers University Press.

Kawahara, D. M. (2007). "Making a difference": Asian American women leaders. Women and Therapy, 30(3-4), 17-33. https://doi.org/10.1300/J015v30n03_03

Kawahara, D. M., Esnil, E. M., \& Hsu, J. (2007). Asian American women leaders: The intersection of race, gender, and leadership. In B. L. J. L. Chin, J. K. Rice \& J. SanchezHucles (Eds.), Women and leadership: Transforming visions and diverse voices (pp. 297-313). Malden, MA: Blackwell Publishing.

Kawahara, D. M., Pal, M. S., \& Chin, J. L. (2013). The leadership experiences of Asian Americans. Asian American Journal of Psychology, 4(4), 240-248. http://dx.doi.org.pitt.idm.oclc.org/10.1037/a0035196

Kawahara, D. M., Tsong, Y., \& Liu, J. (2020). The long and winding road of being and becoming. Women and Therapy, 43(1-2), 74-90. doi:10.1080/02703149.2019.1684684.

Kratt, D. (2018). Teachers' perspectives on educator mental health competencies: A qualitative case study. American Journal of Qualitative Research, 2(1), 22-40.

Lee, J., \& Zhou, M. (2015). The Asian American Achievement Paradox. Sage.

Li, G., \& Beckett, G. H. (2006). "Strangers" of the academy: Asian women scholars in higher education. Sterling, VA: Stylus Publishing, LLC.

Liang, J. G, Sottile, J., \& Peters, A. L. (2016). Understanding Asian American women's pathways to school leadership. Gender and Education, 30, 623-641.

Liang, J., \& Peters-Hawkins, A. L. (2017). "I am more than what I look alike": Asian American women in public school administration. Educational Administration Quarterly, 53(1), 40-69.

Lincoln, Y., \& Guba, E. (1985). Naturalistic inquiry. Sage.

Loo, C. M., \& Ho, H. Z. (2006). Asian American women in the academy. In G. Li, \& G. H. Beckett (Eds.), "Strangers" of academy (pp. 134-160). Sterling, VAL Stylus Publishing, LLC.

Lopez, G. R., Neil G., \& Patten, E. (2017). Key facts about Asian Americans, a diverse and growing population. http://www.pewresearch.org/fact-tank/2017/09/08/key-factsabout-asian-americans/

Merriam, S. B. (2009). Qualitative Research- A Guide to Design and Implementation. JosseyBass.

Merriam, S.B. (1988) Case Study Research in Education: A Qualitative Approach. Jossey-Bass.

Michaelides, M. P. (April 2008). Emerging themes from early research on self-efficacy beliefs in school mathematics. Electronic Journal of Research in Educational Psychology, 6(1), 219-234.

Miles, M., Huberman, M., \& Saldana, J. (2020). Qualitative data analysis - A methods sourcebook. Sage.

Nguyen, C. (2016). Asian American women faculty: Stereotypes and triumphs. In B. Taylor (Ed.), Listening to the voices: Mutli- ethnic women in education (pp. 129-136). University of San Francisco.

Nguyen, P., Corona, R., DeCarlo, M. P., Yaros, A., Le, A. T., \& Compton, K. (2018). Help Seeking Behavior in a Diverse Sample of Asian American Adults. Journal of Ethnic and Cultural Studies, 5(2), 1-15. 
Northouse, P. (2016a). Leadership: Theory and practice (7th ed.). Thousand Oaks, CA: Sage.

Northouse, P. (2016b). Culture and leadership. In P. Northouse (Ed.), Leadership - Theory and practice (7th ed., pp. 427-466). Sage.

Northouse, P. G. (2019). Leadership. Sage.

Northouse, P. G. (2019). Leadership. Thousand Oaks, CA: Sage.

Park, Y., Maramba, D., \& Hernandez, X. (2014). Asian Americans in higher education: Charting new realities (Vol. 40). John Wiley \& Sons, Inc.: ASHE Higher Education Report.

Prinster, R. (2016). Asians and Pacific Islanders are scarce in higher Ed leadership, but a strong community is working to change that. Insight into Diversity. https://www.insightintodiversity.com/asians-and-pacific-islanders-are-scarce-inhigher-ed-leadership-but-a-strong-community-is-working-to-change-that/

Punnakitikashem, P., \& Hallinger, P. (2019). Bibliometric review of the knowledge base on healthcare management for sustainability, 1994-2018. Sustainability, 12(205), 1-17. https://doi.org/10.3390/su12010205

Reeves, M. (2014). Leadership journeys of Asian women in US higher education: A narrative research study exploring leadership development experiences through critical reflection [Doctoral dissertation]. Northeastern University.

Saldana, J. (2016). The coding manual for qualitative researchers (4th ed.). Sage.

Schunk, D. H., Pintrich, P. R., \& Meece, J. L. (2008). Motivation in education: Theory, research, and application (3rd ed.). Upper Saddle River, NJ: Merrill/Prentice-Hall.

Stake, R. E. (1995). The art of case study research. Sage.

Tierney, W. G., Campbell, C. D., \& Sanchez, G. J. (2004). The road ahead: Improving diversity in graduate education. Center for Higher Education Policy Analysis, Rossier School of Education, University of Southern California.

U.S. Census Bureau. (2010). U.S. Census Bureau. www.census.gov

U.S. Census Bureau. (2016). American Community Survey. (2016). US Census Bureau. www.census.gov

Usher, E. L., \& Pajares, F. (2009). Sources of self-efficacy in mathematics: A validation study. Contemporary Educational Psychology, 34, 89-101.

Wu, B. \& Ida, K., A. (2018). Ethnic Diversity, Religion, and Opinions toward Legalizing Abortion: The Case of Asian Americans. Journal of Ethnic and Cultural Studies, 5(1), 94-109.

Yin, R. (2003). Case study research: Design and methods (applied social research methods) (5th ed.). Sage.

\section{Biographical Notes}

Dao Nguyen is Program Coordinator at the Institute for International Studies in Education (IISE) at the University of Pittsburgh (the United States), and Research Fellow at the IRED Institute of Education (Vietnam). She has over 20 years of work experience in the capacities of practitioner, advocate, manager, researcher, and policy-maker in the fields of education and international relations. Co-currently, she is a Ph.D. student, majoring in Higher Education Management; and minoring in Gender-Sexuality-Women Studies, Research Methodology, Asian Studies, and Global Studies at the University of Pittsburgh. 